\title{
Using personalized medicine in gliomas: a genomic approach to diagnosis and overcoming treatment resistance in a case with pleomorphic xanthoastrocytoma
}

\author{
Yolanda Piña ${ }^{1}$. $\cdot$ Michael J. Fusco ${ }^{1} \cdot$ Robert J. Macaulay ${ }^{1} \cdot$ Christine M. Walko $^{1} \cdot$ Edwin Peguero $^{1}$. \\ Brittany R. Evernden ${ }^{1} \cdot$ Keiran S. Smalley ${ }^{1}$ Peter Forsyth ${ }^{1}$
}

Received: 11 July 2019 / Revised: 30 September 2019 / Accepted: 3 October 2019 / Published online: 21 November 2019

(c) The Author(s) 2019

\begin{abstract}
Introduction A patient who was initially considered to have a glioblastoma (GBM) had molecular analysis, showing that it was a pleomorphic xanthoastrocytoma (PXA). Up to 78\% of PXA tumors have BRAF V600E mutations. Primary brain tumors with $B R A F$ mutations can have a good response to $B R A F$ MEK inhibitors (BRAF MEKi), and there may be a synergistic response when combined with autophagy inhibitors.

Presentation of the case A 20-year-old man found to have a large brain mass with midline shift underwent resection. He was diagnosed with "GBM" and treated with radiation and temozolomide with subsequent disease recurrence. Review of histology showed malignant PXA with BRAF V600E mutation. Treatment with Dabrafenib and Trametinib was started, and tumor size increased in size after 14 months of treatment. Given studies showing that resistance to $B R A F$ inhibition can be overcome by autophagy inhibition, chloroquine was added. Patient has been on "triple" therapy for 15 months and has radiographically Stable Disease. At MCC, $3 \%$ of patients with gliomas have BRAF mutations who could potentially benefit from this combination therapy.

Conclusion This is the first report of a PXA patient receiving therapy with BRAF MEKi and an autophagy inhibitor with prolonged stable disease. This patient highlights the importance of a molecular interrogation in gliomas to provide an integrated diagnosis and effective treatment. This may be useful in up to 3\% of glioma patients with BRAF mutations. Molecular testing in neuro-oncology is providing new avenues of diagnosis and treatment, and detailed molecular interrogation should be considered routine.
\end{abstract}

Keywords Pleomorphic xanthoastrocytoma $B R A F$ inhibition $\cdot M E K$ inhibition $\cdot$ V600E mutation - Autophagy inhibition Chloroquine

\section{Introduction}

Pleomorphic xanthoastrocytoma (PXA) is a rare low-grade astrocytoma, which accounts for less than $1 \%$ of all central nervous system (CNS) neoplasms. It is most commonly found in children and young adults. It is characterized by spindle-shaped or pleomorphic astrocytes with frequent intracytoplasmic lipid vacuoles, moderate-to-marked nuclear atypia, eosinophilic granular bodies, frequent desmoplasia,

Yolanda Piña

yolanda.pina@moffitt.org

1 H. Lee Moffitt Cancer Center \& Research Institute, 12902 USF Magnolia Dr., Tampa, FL 33617, USA and patchy chronic inflammation. Mitotic activity is usually sparse. PXA is usually low grade, but may be anaplastic as in the current case report. Recently, a growing body of evidence has shifted the classification of gliomas based on histological and molecular findings, with PXA and anaplastic PXA perceived as separate entities, and classified by the World Health Organization (WHO) as grade II and III, respectively. This is mainly based on the mitotic index (MI), with WHO grade III based on MI equal to or greater than 5 mitotic cells per every 10 high power field (HPF), with or without accompanying necrosis [1,2]. Magnetic Resonance Imaging (MRI) of the brain demonstrates either a solid mass or a solid-cystic pattern with the cystic component hypointense on T1-weighted images and hyperintense on $\mathrm{T} 2$, and the solid component showing contrast enhancement that 
is hypo- or isointense on T1-weighted images and iso- or slightly hyperintense on $\mathrm{T} 2[3,4]$.

Sixty to seventy-eight percent of PXA tumors have a $B R A F \mathrm{~V} 600 \mathrm{E}$ mutation. This mutation is frequently found in PXA and has allowed targeted molecular therapy in many other different tumor types [5-10]. There are few clinical trials in $B R A F$-mutated gliomas. The VE-BASKET study, which treated a wide range of glioma patients with $B R A F$ V600 mutation with $B R A F$ inhibition, showed a PXA case with a complete response (14\% of PXA treated, $n=7$, and $4 \%$ of all gliomas, $n=24$ ), two cases with partial responses (29\% of PXA, and $8 \%$ of all gliomas), and three cases with stable disease ( $43 \%$ of PXA, and $12.5 \%$ of all gliomas). The median progression-free survival was 5.5 months in all the gliomas treated, and more than 39.1 months in a PXA case [11]. There are several case reports of combined BRAF MEKi in PXA patients [12-14]. As well as an enhanced response to $B R A F$ inhibition when combined with autophagy inhibition in glioma cell lines [15]. However, experience with BRAF MEKi with the addition of chloroquine has not been published in PXAs. Here, we present a patient with a malignant PXA with a BRAF V600E mutation, who had a prolonged response to BRAF MEKi and benefited by the addition of chloroquine with an ongoing prolonged disease control.

\section{Case presentation}

A 19-year-old man developed blurry vision with new headaches in November 2014. He had bilateral papilledema. A MRI brain showed a large right-sided lesion involving the parieto-temporal lobes, hyperintense on $\mathrm{T} 1$ and T2-weighted sequences, with significant surrounding vasogenic edema on T2-weighted fluid-attenuated inversion recovery (FLAIR), contrast enhancement post-gadolinium, and a right-to-left midline shift (Fig. 1a, b). The overall appearance of this lesion looked a bit unusual for a classical GBM. He had a subtotal resection on January 30th, 2015, and was diagnosed by a local pathologist with a "GBM". He completed 6 weeks of radiation therapy (RT) and temozolomide (TMZ). Four months later, a follow-up MRI showed an increase in the size of the enhancing tumor and, despite the possibility of pseudoprogression, a second surgical resection was performed on June 2nd, 2015 and showed "GBM". Maintenance TMZ was started and follow-up imaging showed stable disease (Fig. 1).

The patient was referred to the Neuro-Oncology clinic at MCC in June 2015. Histology review showed that he had a malignant PXA grade III-IV, rather than a GBM. It had multinucleated giant cells, prominent nucleoli, and eosinophilic granular bodies on $600 \times \mathrm{HPF}$, and a high mitotic index with dysplastic neurons on $200 \times \mathrm{HPF}$ (Fig. 2).
Histological samples were GFAP positive, with necrosis, ATRX retained, had a proliferation rate of $2 \%$ by Ki-67, and was positive for BRAF V600E on IHC (Fig. 3). Foundation one testing confirmed the BRAF V600E mutation, IDH1 wild-type, and no EGFRviii. Other testing showed that the tumor was negative for $1 \mathrm{p} / 19 \mathrm{q}$ co-deletion and was O6-methylguanine-DNA methyltransferase (MGMT) promoter unmethylated.

After an initial 17 months of stable disease, on his MRI, there was a small increase in the size of his tumor (Fig. 4). Accordingly, combination therapy with $B R A F$ kinase and MEK inhibitors, Dabrafenib $150 \mathrm{mg}$ PO BID and Trametinib $2 \mathrm{mg}$ PO OD, was started on November 2016. As soon as 2 months after starting treatment, there was radiographic evidence of disease regression, though it did not meet the criteria for a Partial Response because of its small size. The patient was continued on this treatment regimen for 10 months and further serial imaging showed stable disease.

After 8 months of treatment, in July 2017, treatment was held to give the patient a "drug holiday," but, 2 months later, his MRI showed disease progression. Dabrafenib and Trametinib were re-started, and he remained stable until January 2018 when he had disease progression with BRAF MEKi. Since resistance to $B R A F$ inhibition can be overcome by autophagy inhibition [15-17], we added the autophagy inhibitor chloroquine (500 mg PO daily) to his BRAF MEKi therapy. Each tablet of chloroquine contains $500 \mathrm{mg}$ of chloroquine phosphate USP and the equivalent to $300 \mathrm{mg}$ chloroquine base, which is the standard, maximal safe dose that is FDA-approved for adults [18].

Based on the Response Assessment in Neuro-Oncology (RANO) criteria, the lesion size was measured, the sum of the perpendicular diameters (SPD) calculated and plotted (Fig. 4). The tumor decreased by more than $25 \%$ after BRAF MEKi was started (Fig. 4a) but unfortunately increased after a drug holiday (Fig. 4c), and continued to grow despite restarting therapy with BRAF MEKi (Fig. 4d), at which point the autophagy inhibitor chloroquine was added halting the rate of tumor progression and even causing a slight decrease in the lesion size (Fig. 4e).

There are no reported potential interactions between chloroquine and Dabrafenib and/or Trametinib. Chloroquine's adverse effects can be multisystemic affecting the eyes (e.g., retinopathy, visual disturbances), hearing, liver, gastrointestinal system (e.g., nausea, vomiting, diarrhea, abdominal cramps), muscles (e.g., myopathy), skin (e.g., erythema multiforme, Stevens-Johnson syndrome), cardiac (e.g., prolonged QT interval), hematologic system (e.g., pancytopenia), and nervous system (e.g., seizures, extrapyramidal signs) [18]. Given these side effects, we had taken precautionary measures with close monitoring every 1-2 months since started triple therapy, checking complete blood cells counts, complete metabolic panels, electrocardiogram, 

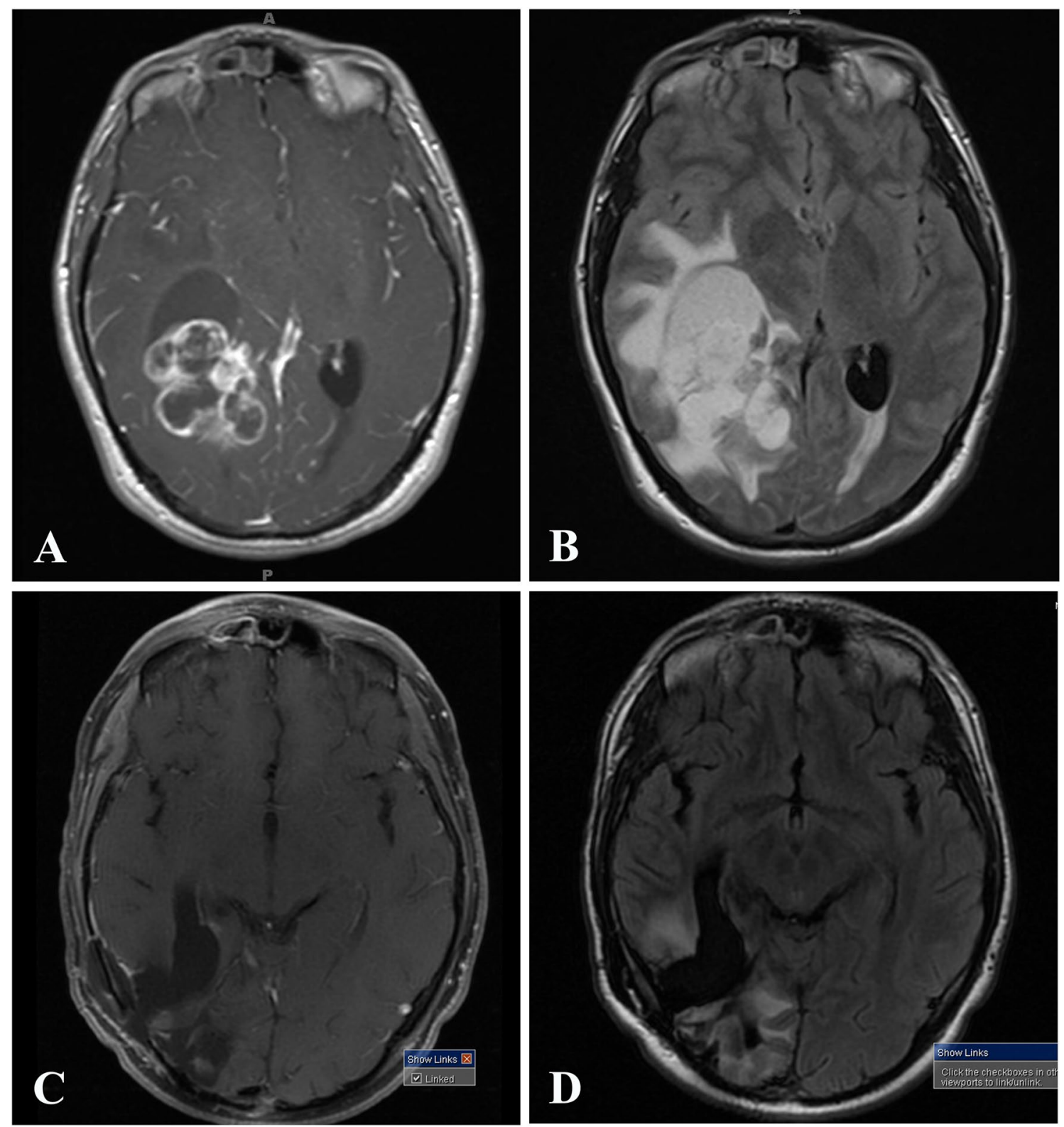

Fig. 1 MRI of the brain demonstrating a right-sided, large parietotemporo-occipital mass, which appeared unusual for a classical GBM, with surrounding vasogenic edema and a right-to-left midline shift. a, b Initial MRI of the brain prior to surgery for tumor resection in January 2015. a T1-weighted post-contrast demonstrating heteroge-

and echocardiograms. Overall, our patient tolerated the triple therapy well for 17 months until recently, when he complained of mild nausea, diarrhea, and a skin rash. The decision was made to hold chloroquine, while continuing Dabrafenib and Trametinib, with plans to re-assess him in 2 months.

In summary, radiographically, he has had Stable Disease with BRAF MEKi for 14 months, and later with the addition of chloroquine for a total of $>2.5$ years of treatment (triple therapy for 17 months), without major side effects from the

neous enhancement. b T2-weighted fluid-attenuated inversion recovery (FLAIR) shows significant surrounding vasogenic edema. c, d Status-post resection and two cycles of maintenance TMZ in September 2015. c T1-weighted post-contrast. d Status-post resection, T2-weighted FLAIR sequence

treatment, until recently for which he is receiving a drug holiday from chloroquine.

\section{Discussion}

PXA is a rare low-grade astrocytoma, which may be anaplastic, as in the case herein presented. An MRI can show either a solid mass or a solid-cystic lesion, with the cystic component being hypointense on $\mathrm{T} 1$ and hyperintense on 

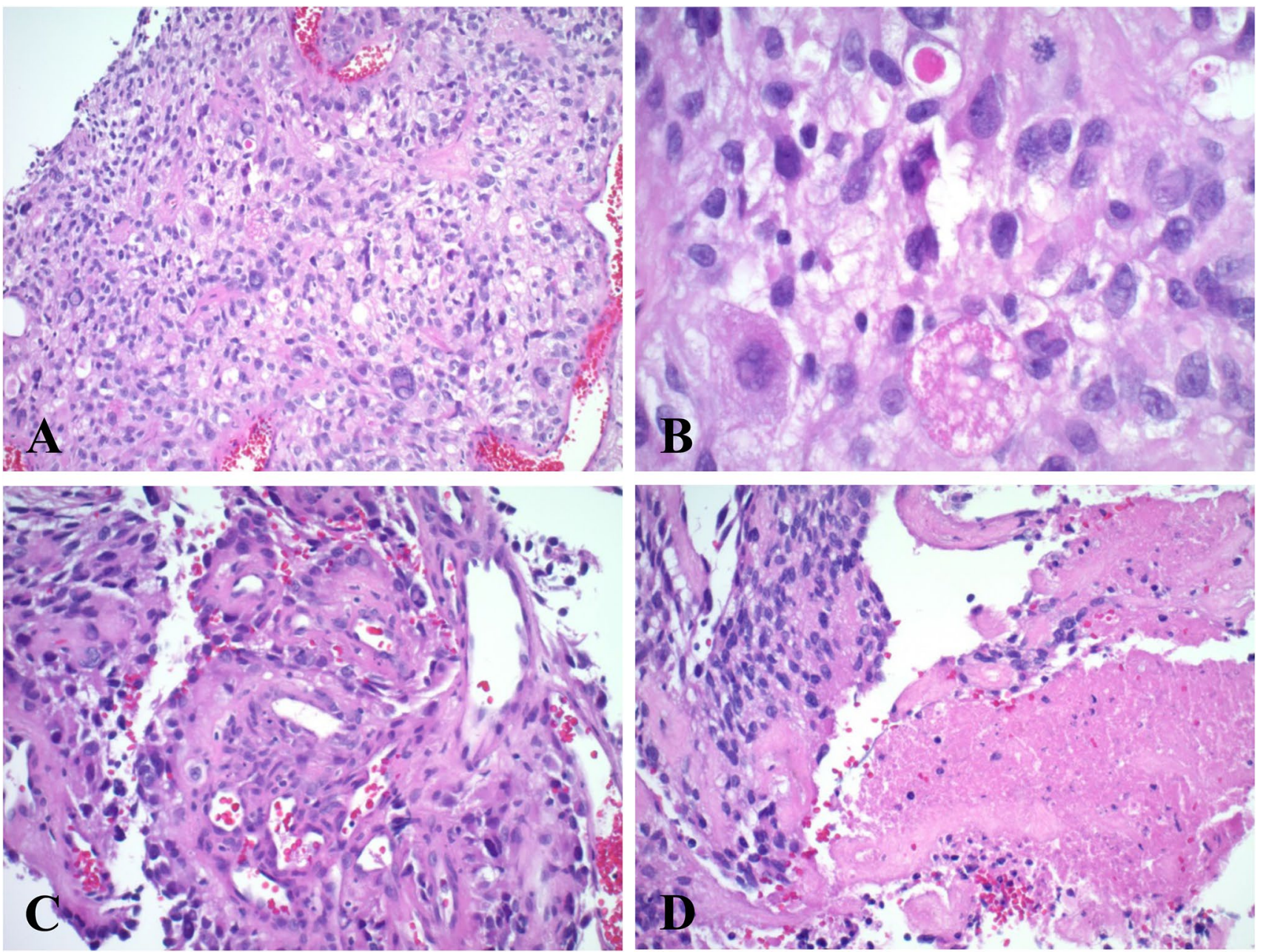

Fig. 2 Histology of tumor sample demonstrating an atypical malignant glioma that resembled a PXA rather than a GBM. a Non-infiltrating tumor, WHO grade III-IV, H\&E, $\times 20$ HPF. b Neoplastic

T2, and the solid component having contrast enhancement that is hypo- or isointense on T1 and iso- or slightly hyperintense on T2 [3, 4]. These radiographic findings make it possible to misdiagnose this as a malignant glioma or a GBM. Histologically, PXA is composed of neoplastic astrocytes and multinucleated giant cells with prominent nucleoli and/ or nuclear vacuolation, with immunoreactivity to $\mathrm{S} 100$ protein and GFAP [19]. Sixty to seventy-eight percent of PXA tumors have been found to carry $B R A F$ V600E mutation, which was more frequently found in PXA tumors than in any other neuroepithelial neoplasm of the CNS [5-10]; it can be detected via immunohistochemistry [20] or by molecular techniques. The relationship of anaplastic PXA to epithelioid glioblastomas, which also carry the BRAF V600E alteration, remains unsettled.

$B R A F \mathrm{~V} 600 \mathrm{E}$ mutations result in the constitutive activation of the $B R A F$ pathway, which includes mitogen-activated extracellular signal kinase (MEK) 1 and 2 activation. This

astrocytes and binucleated giant cells, with prominent nucleoli, nuclear vacuolation, and eosinophilic granular bodies, H\&E, $\times 600$ HPF. c Vascular proliferation, $\times 200$ HPF. d Necrosis, $\times 200 \mathrm{HPF}$

mutation is found in a number of primary brain gliomas, including PXAs [7, 9, 21, 22], gangliogliomas, and papillary craniopharyngiomas [23]. Dabrafenib (Tanfinlar ${ }^{\circledR}$ ) is a $B R A F$ kinase inhibitor approved by the U.S. FDA for $B R A F$ V600E melanomas [24]. Metastatic melanoma tumors with $B R A F$ V600E mutations have a complete $(6 \%)$ or partial tumor regression $(62.5 \%)$ in most patients treated with the $B R A F$ inhibitor [25]. Combination therapy with Dabrafenib and Trametinib (Mekinist ${ }^{\circledR}$ ), an MEK 1 and 2 inhibitor, produces superior response rate to BRAF inhibition alone and has been approved for metastatic melanoma with either BRAF V600E or V600K mutations [26].

Several Clinical Trials have shown that $B R A F$ inhibition monotherapy (e.g., vemurafenib) is effective in melanoma brain metastases [27-30] and small case series have shown that several primary BRAF mutant brain tumors (i.e., primary neuroepithelial brain tumors, malignant astrocytomas, papillary craniopharyngiomas, and other nonmelanoma 

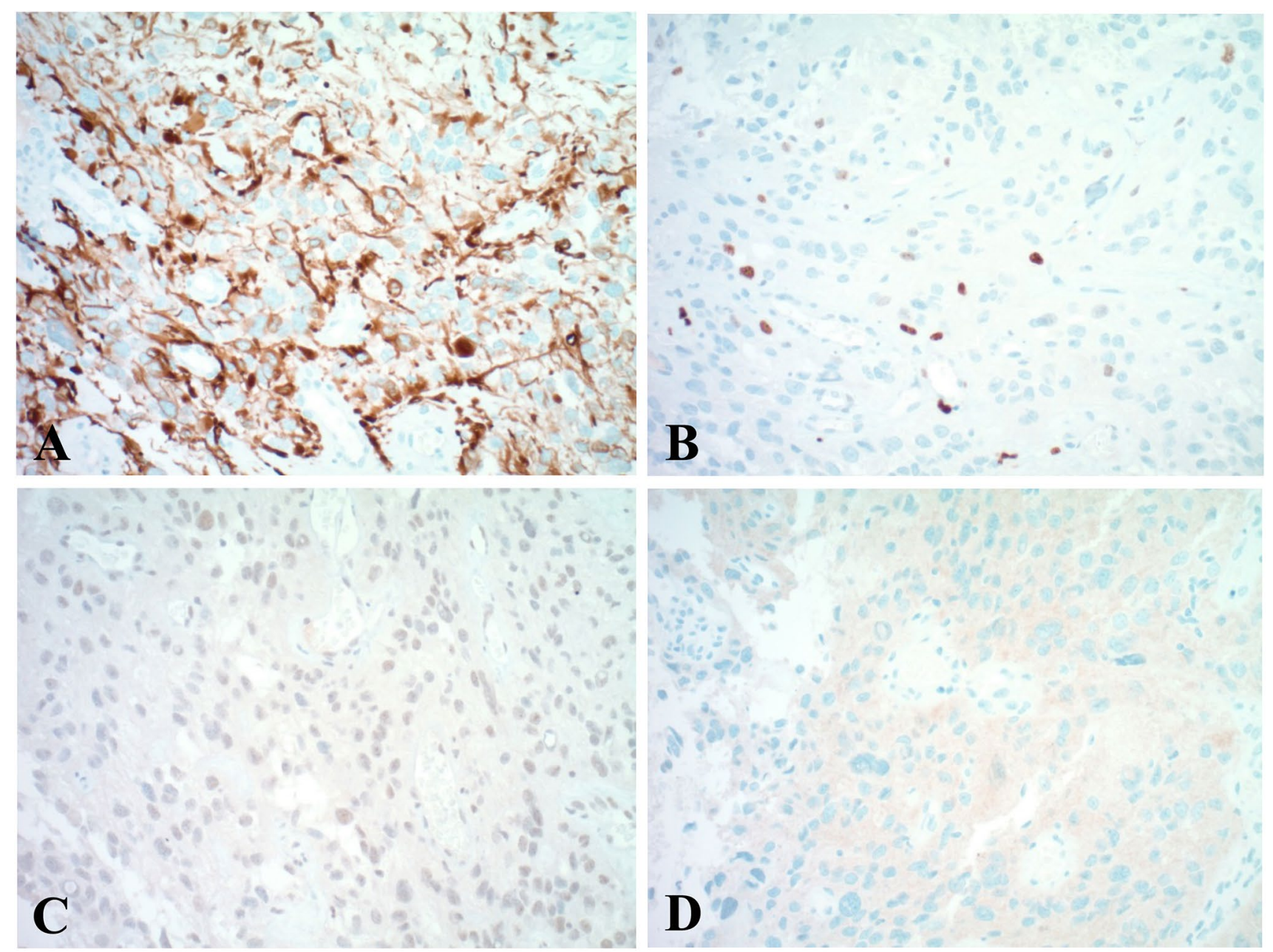

Fig. 3 Immunohistochemistry (original magnification $\times 200$ HPF). Tumor cells: a were GFAP-positive; b had a Ki-67 proliferation index of $2 \%$; c retained ATRX; and $\mathbf{d}$ were diffusely positive for $B R A F \mathrm{~V} 600 \mathrm{E}$

cancers) also respond to $B R A F$ inhibition [21, 23, 31, 32]. Surprisingly, papillary craniopharyngiomas have $B R A F$ mutations and patients may respond dramatically [23]. Others have reported $B R A F$ mutant anaplastic PXAs having partial responses to $B R A F$ inhibitor monotherapy [31,33]. And, more recently, there are reports of BRAF MEKi. Similarly, few case reports have shown promising results after combination therapy with BRAF MEKi in PXA patients with $B R A F$ mutations [12-14].

Unfortunately, tumors often develop resistance to targeted therapies, and hence, approaches to overcome resistance to BRAF MEKi would be very useful [22, 34]. One such approach is by inhibiting autophagy. Maddodi et al. showed that autophagy is triggered by hyperactivation of the ERK pathway by upstream $B R A F$ activating mutations in melanomas in vitro and in vivo. [35] Autophagy inhibition in $B R A F$ mutant melanoma animal inhibits tumor growth and prolongs survival [34]. In addition, high autophagic index in melanomas correlates with short survival and autophagy inhibition is effective in vitro. [36] Similar results are seen in $B R A F \mathrm{~V} 600 \mathrm{E}$ lung, and pancreatic and colorectal cancers, and hence, this is not tumor type specific $[37,16]$. This strategy of combining autophagy inhibition with $B R A F$ inhibition monotherapy in brain tumors was demonstrated in several brain tumors, including PXAs, using chloroquine [15-17]. Therefore, we combined BRAF MEKi with chloroquine and transformed a radiographically growing tumor (Fig. 4c, d) into a long (> 18 months) and sustained stability of disease in a patient without side effects for almost 1.5 years. This supports the hypothesis that autophagy inhibition can make brain tumors with $B R A F$ mutations more chemosensitive to $B R A F$ inhibition.

The current case report has several limitations, which include the lack of ability to generalize, risk of misinterpretation, and no established cause-effect relationship. As a single case report, findings cannot be generalized to represent similar groups of patients, partly for its dearth of an established cause-effect association from therapy, which can 


\section{Tumor size and response to treatment}

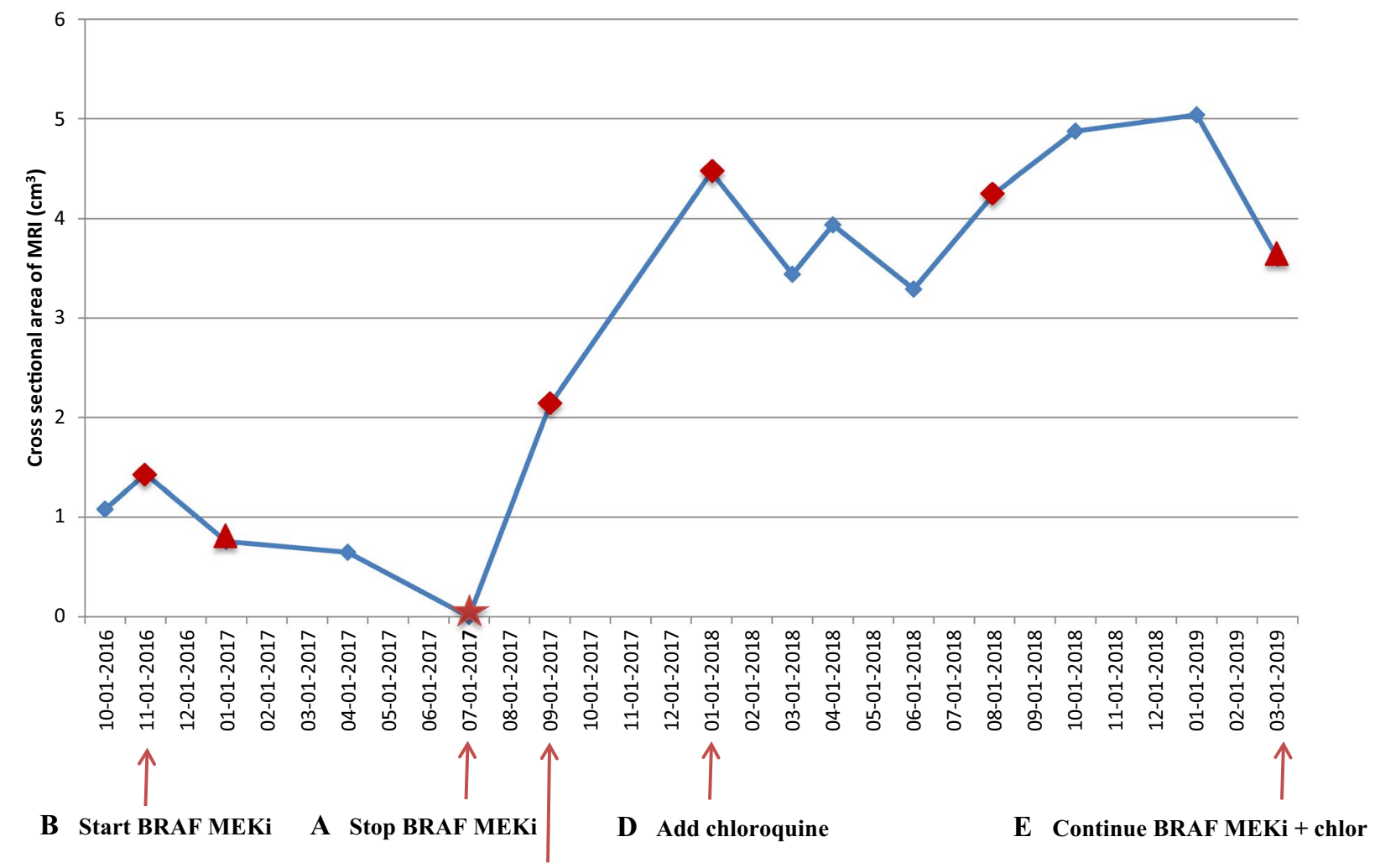

C Re-start BRAF MEKi

A
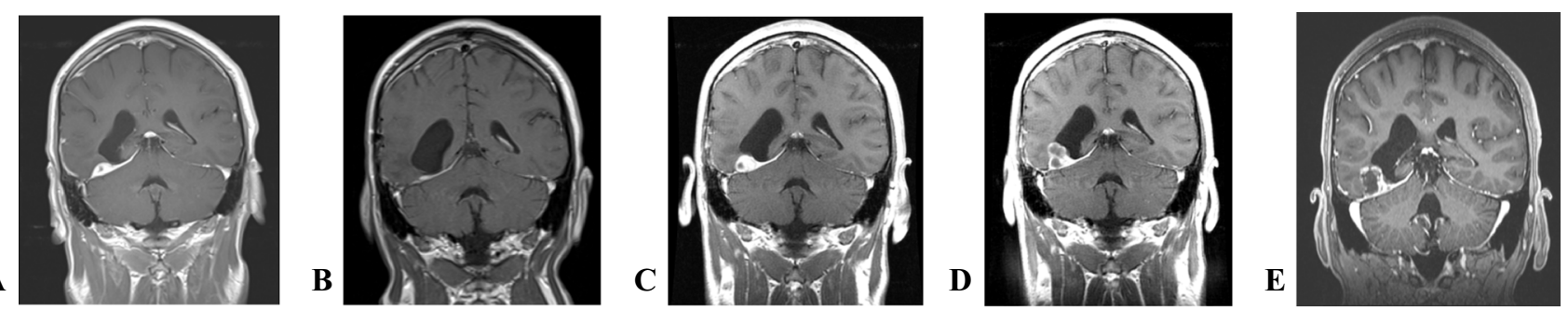

Fig. 4 Lesion size changes based on RANO criteria and response to treatment. a Dabrafenib and trametinib combination therapy was initiated. b Treatment was discontinued for a holiday and re-started after disease progression (c). d Autophagy inhibitor was added to dabrafenib and trametinib. e Last MRI brain showed slight decrease in the size of the mass and the central cystic component measuring
$1.9 \times 1.6 \mathrm{~cm}$, compared to prior measuring $2.1 \times 1.5 \mathrm{~cm} 2$ months earlier; there were no changes in the peripheral enhancing aspect of the lesion. Target lesion response measured by RANO criteria. $\mathrm{Star}=\mathrm{CR}$ (all target lesions disappeared). Triangle $=\mathrm{SD}(\mathrm{SPD}<50 \%$ decrease to $<25 \%$ increase). Rhomboid $=$ PD (SPD increased by $\geq 25 \%$ from nadir value)

importance of a molecular interrogation of gliomas to provide an integrated diagnosis in gliomas and effective targeted treatment. Encouraged by these results, we reviewed glioma cases at Moffitt Cancer Center (MCC), who had similar molecular profiling, and found $3 \%$ patients with gliomas carrying $B R A F$ mutations. These patients could potentially benefit from treatment with BRAF MEKi in combination with chloroquine. Molecular testing in neuro-oncology is providing new avenues of diagnosis and treatment, and detailed molecular interrogation should be considered routine. 


\section{Compliance with ethical standards}

Conflicts of interest The authors of this manuscript have no conflict of interest to report.

Ethical standards The current article does not contain any studies with humans or animals performed by any of the authors.

Informed consent The patient has given his informed consent for the case report to be published.

Open Access This article is distributed under the terms of the Creative Commons Attribution 4.0 International License (http://creativeco mmons.org/licenses/by/4.0/), which permits unrestricted use, distribution, and reproduction in any medium, provided you give appropriate credit to the original author(s) and the source, provide a link to the Creative Commons license, and indicate if changes were made.

\section{References}

1. Giannini C, Scheithauer BW, Burger PC, Brat DJ, Wollan PC, Lach B, O'Neill BP (1999) Pleomorphic xanthoastrocytoma: what do we really know about it? Cancer 85(9):2033-2045

2. Wesseling P, Capper D (2018) WHO 2016 classification of gliomas. Neuropathol Appl Neurobiol 44(2):139-150

3. Goncalves VT, Reis F, Queiroz Lde S, Franca M Jr (2013) Pleomorphic xanthoastrocytoma: magnetic resonance imaging findings in a series of cases with histopathological confirmation. Arq Neuropsiquiatr 71(1):35-39

4. Yu S, He L, Zhuang X, Luo B (2011) Pleomorphic xanthoastrocytoma: MR imaging findings in 19 patients. Acta Radiol 52(2):223-228

5. Bettegowda C, Agrawal N, Jiao Y, Wang Y, Wood LD, Rodriguez FJ, Hruban RH, Gallia GL, Binder ZA, Riggins CJ et al (2013) Exomic sequencing of four rare central nervous system tumor types. Oncotarget 4(4):572-583

6. Chappe C, Padovani L, Scavarda D, Forest F, Nanni-Metellus I, Loundou A, Mercurio S, Fina F, Lena G, Colin C et al (2013) Dysembryoplastic neuroepithelial tumors share with pleomorphic xanthoastrocytomas and gangliogliomas BRAF(V600E) mutation and expression. Brain Pathol 23(5):574-583

7. Dias-Santagata D, Lam Q, Vernovsky K, Vena N, Lennerz JK, Borger DR, Batchelor TT, Ligon KL, Iafrate AJ, Ligon AH et al (2011) BRAF V600E mutations are common in pleomorphic xanthoastrocytoma: diagnostic and therapeutic implications. PLoS ONE 6(3):e17948

8. Ida CM, Rodriguez FJ, Burger PC, Caron AA, Jenkins SM, Spears GM, Aranguren DL, Lachance DH, Giannini C (2015) Pleomorphic xanthoastrocytoma: natural history and long-term follow-up. Brain Pathol 25(5):575-586

9. Schindler G, Capper D, Meyer J, Janzarik W, Omran H, HeroldMende C, Schmieder K, Wesseling P, Mawrin C, Hasselblatt M et al (2011) Analysis of BRAF V600E mutation in 1,320 nervous system tumors reveals high mutation frequencies in pleomorphic xanthoastrocytoma, ganglioglioma and extra-cerebellar pilocytic astrocytoma. Acta Neuropathol 121(3):397-405

10. Zhang J, Wu G, Miller CP, Tatevossian RG, Dalton JD, Tang B, Orisme W, Punchihewa C, Parker M, Qaddoumi I et al (2013) Whole-genome sequencing identifies genetic alterations in pediatric low-grade gliomas. Nat Genet 45(6):602-612

11. Kaley T, Touat M, Subbiah V, Hollebecque A, Rodon J, Lockhart AC, Keedy V, Bielle F, Hofheinz RD, Joly F et al (2018) BRAF inhibition in BRAF(V600)-mutant gliomas: results from the VE-BASKET study. J Clin Oncol Off J Am Soc Clin Oncol 36:JCO2018789990

12. Hussain F, Horbinski CM, Chmura SJ, Yamini B, Lukas RV (2018) Response to BRAF/MEK inhibition after progression with BRAF inhibition in a patient with anaplastic pleomorphic xanthoastrocytoma. Neurologist 23(5):163-166

13. Amayiri N, Swaidan M, Al-Hussaini M, Halalsheh H, Al-Nassan A, Musharbash A, Tabori U, Hawkins C, Bouffet E (2018) Sustained response to targeted therapy in a patient with disseminated anaplastic pleomorphic xanthoastrocytoma. J Pediatr Hematol Oncol 40(6):478-482

14. Brown NF, Carter T, Kitchen N, Mulholland P (2017) Dabrafenib and trametinib in BRAFV600E mutated glioma. CNS Oncol 6(4):291-296

15. Mulcahy Levy JM, Zahedi S, Griesinger AM, Morin A, Davies KD, Aisner DL, Kleinschmidt-DeMasters BK, Fitzwalter BE, Goodall ML, Thorburn J et al (2017) Autophagy inhibition overcomes multiple mechanisms of resistance to BRAF inhibition in brain tumors. Elife 6:e19671

16. Kinsey CG, Camolotto SA, Boespflug AM, Guillen KP, Foth M, Truong A, Schuman SS, Shea JE, Seipp MT, Yap JT et al (2019) Publisher correction: protective autophagy elicited by $\mathrm{RAF} \rightarrow \mathrm{MEK} \rightarrow \mathrm{ERK}$ inhibition suggests a treatment strategy for RAS-driven cancers. Nat Med 25:620-627

17. Levy JM, Thompson JC, Griesinger AM, Amani V, Donson AM, Birks DK, Morgan MJ, Mirsky DM, Handler MH, Foreman NK et al (2014) Autophagy inhibition improves chemosensitivity in BRAF(V600E) brain tumors. Cancer Discov 4(7):773-780

18. Food and Drug Administration (FDA) Drug and safety data sheet (2013). FDA: aralen chloroquine phosphate, USP. Reference ID: 3402523. http://www.accessdata.fda.gov/drugsatfda_docs/label /2013/006002s043lbl.pdf

19. Louis DN, Ohgaki H, Wiestler OD, Cavenee WK, Burger PC, Jouvet A, Scheithauer BW, Kleihues P (2007) The 2007 WHO classification of tumours of the central nervous system. Acta Neuropathol 114(2):97-109

20. Ida CM, Vrana JA, Rodriguez FJ, Jentoft ME, Caron AA, Jenkins SM, Giannini C (2013) Immunohistochemistry is highly sensitive and specific for detection of BRAF V600E mutation in pleomorphic xanthoastrocytoma. Acta Neuropathol Commun 1:20

21. Nicolaides TP, Li H, Solomon DA, Hariono S, Hashizume R, Barkovich K, Baker SJ, Paugh BS, Jones C, Forshew T et al (2011) Targeted therapy for BRAFV600E malignant astrocytoma. Clin Cancer Res 17(24):7595-7604

22. Hartsough E, Shao Y, Aplin AE (2014) Resistance to RAF inhibitors revisited. J Investig Dermatol 134(2):319-325

23. Brastianos PK, Shankar GM, Gill CM, Taylor-Weiner A, Nayyar N, Panka DJ, Sullivan RJ, Frederick DT, Abedalthagafi M, Jones PS et al (2015) Dramatic response of BRAF V600E mutant papillary craniopharyngioma to targeted therapy. J Natl Cancer Inst 108(2):djv310. https://doi.org/10.1093/jnci/djv310

24. Hauschild A, Grob JJ, Demidov LV, Jouary T, Gutzmer R, Millward M, Rutkowski P, Blank CU, Miller WH Jr, Kaempgen E et al (2012) Dabrafenib in BRAF-mutated metastatic melanoma: a multicentre, open-label, phase 3 randomised controlled trial. Lancet 380(9839):358-365

25. Flaherty KT, Puzanov I, Kim KB, Ribas A, McArthur GA, Sosman JA, O'Dwyer PJ, Lee RJ, Grippo JF, Nolop K et al (2010) Inhibition of mutated, activated BRAF in metastatic melanoma. N Engl J Med 363(9):809-819

26. Owens GM (2015) New FDA drug approvals hit an 18-year high in 2014. Am Health Drug Benefits 8(Spec Feature):15-17

27. Chapman PB, Robert C, Larkin J, Haanen JB, Ribas A, Hogg D, Hamid O, Ascierto PA, Testori A, Lorigan PC et al (2017) Vemurafenib in patients with BRAFV600 mutation-positive 
metastatic melanoma: final overall survival results of the randomized BRIM-3 study. Ann Oncol 28(10):2581-2587

28. Dummer R, Goldinger SM, Turtschi CP, Eggmann NB, Michielin O, Mitchell L, Veronese L, Hilfiker PR, Felderer L, Rinderknecht JD (2014) Vemurafenib in patients with BRAF(V600) mutationpositive melanoma with symptomatic brain metastases: final results of an open-label pilot study. Eur J Cancer 50(3):611-621

29. Flaherty L, Hamid O, Linette G, Schuchter L, Hallmeyer S, Gonzalez R, Cowey CL, Pavlick A, Kudrik F, Curti B et al (2014) A single-arm, open-label, expanded access study of vemurafenib in patients with metastatic melanoma in the United States. Cancer J 20(1):18-24

30. McArthur GA, Chapman PB, Robert C, Larkin J, Haanen JB, Dummer R, Ribas A, Hogg D, Hamid O, Ascierto PA et al (2014) Safety and efficacy of vemurafenib in BRAF(V600E) and BRAF(V600K) mutation-positive melanoma (BRIM-3): extended follow-up of a phase 3, randomised, open-label study. Lancet Oncol 15(3):323-332

31. Hyman DM, Puzanov I, Subbiah V, Faris JE, Chau I, Blay JY, Wolf J, Raje NS, Diamond EL, Hollebecque A et al (2015) Vemurafenib in multiple nonmelanoma cancers with BRAF V600 mutations. N Engl J Med 373(8):726-736

32. Preusser M, Bienkowski M, Birner P (2016) BRAF inhibitors in BRAF-V600 mutated primary neuroepithelial brain tumors. Expert Opin Investig Drugs 25(1):7-14
33. Usubalieva A, Pierson CR, Kavran CA, Huntoon K, Kryvenko ON, Mayer TG, Zhao W, Rock J, Ammirati M, Puduvalli VK et al (2015) Primary meningeal pleomorphic xanthoastrocytoma with anaplastic features: a report of 2 cases, one with $\mathrm{BRAF}(\mathrm{V} 600 \mathrm{E})$ mutation and clinical response to the BRAF inhibitor dabrafenib. J Neuropathol Exp Neurol 74(10):960-969

34. Xie X, Koh JY, Price S, White E, Mehnert JM (2015) Atg7 overcomes senescence and promotes growth of BrafV600E-driven melanoma. Cancer Discov 5(4):410-423

35. Maddodi N, Huang W, Havighurst T, Kim K, Longley BJ, Setaluri V (2010) Induction of autophagy and inhibition of melanoma growth in vitro and in vivo by hyperactivation of oncogenic BRAF. J Investig Dermatol 130(6):1657-1667

36. Ma XH, Piao S, Wang D, McAfee QW, Nathanson KL, Lum JJ, Li LZ, Amaravadi RK (2011) Measurements of tumor cell autophagy predict invasiveness, resistance to chemotherapy, and survival in melanoma. Clin Cancer Res 17(10):3478-3489

37. Strohecker AM, Guo JY, Karsli-Uzunbas G, Price SM, Chen GJ, Mathew R, McMahon M, White E (2013) Autophagy sustains mitochondrial glutamine metabolism and growth of BrafV600Edriven lung tumors. Cancer Discov 3(11):1272-1285 